\title{
Measuring saproxylic beetle diversity in small and medium diameter dead wood: The "grab-and-go" method
}

\author{
AnNA L.M. MACAGNO ${ }^{1,2}$, SöNKe HARDERSEN ${ }^{1}$, GiANLUCA NARDI ${ }^{1}$, Giuseppe LO GIUDICE ${ }^{1,2}$ \\ and FRANCO MASON ${ }^{1}$ \\ ${ }^{1}$ CNBFVR - Centro Nazionale per lo Studio e la Conservazione della Biodiversità Forestale "Bosco Fontana" di Verona, \\ Corpo Forestale dello Stato, Strada Mantova 29, 46045 Marmirolo (MN), Italy; e-mails: anna.macagno@gmail.com; \\ s.hardersen@gmail.com; 1_nardi@hotmail.com; fmason@tin.it \\ ${ }^{2}$ Dipartimento di Biologia e Biotecnologie "Charles Darwin”, Sapienza Università di Roma, Via Borelli 50, 00161 Roma, Italy; \\ e-mail: giuseppelogiudice78@gmail.com
}

Key words. Coleoptera, saproxylic beetles, Alps, Apennines, biodiversity, emergence trap, Fagus sylvatica, "grab-and-go" method

\begin{abstract}
Saproxylic organisms play a key role in a variety of forest ecosystem functions, which result in an increase in overall forest productivity and biodiversity. At present, dead wood is frequently removed from exploited forests. Estimating the effect of current forest management on biodiversity, and what gain in biodiversity would result from implementing restoration programs, requires the use of standardized sampling protocols. These protocols need to be suitable for use in different sampling areas and cost effective. In this paper, we developed, tested, and optimized a method for sampling saproxylic insects during a single visit to a sample site (i.e., the "grab-and-go" method). In the spring of 2011, we collected samples of downed decaying small and medium diameter wood debris in two Italian beech forests: Sega di Ala (Alps) and Vallombrosa (Apennines). We used ex situ emergence traps in the laboratory to collect the beetles emerging from the wood sampled. At both sites, the minimum number of wood samples that resulted in a satisfactory description of the saproxylic beetle assemblage was 20 . Wood moisture, mean diameter, and geographical location were significantly associated with the beetle assemblages. We discuss the implications of using the "grab-and-go" method in large-scale forest monitoring programs. In this context, we recommend collecting at each site twenty $50 \mathrm{~cm}$-long samples of wood lying on top of the litter, with a diameter of $12 \pm 2 \mathrm{~cm}$, cortex cover $<50 \%$, and at Hunter's stage of decay class 2 .
\end{abstract}

\section{INTRODUCTION}

Dead wood is an important resource for forest biodiversity (Stokland et al., 2012). "Species of invertebrate that are dependent, during some part of their life cycle, upon the dead or dying wood of moribund or dead trees [...], or upon wood-inhabiting fungi, or upon the presence of other saproxylics" are defined as saproxylic (Speight, 1989), and are an extremely species rich and functionally important component of forest ecosystems (Grove, 2002; Stokland et al., 2012). By accelerating the natural process of wood decay, they play a key role in carbon capture, soil enrichment, and nutrient cycling, thus increasing overall forest productivity and biodiversity (Cavalli \& Mason, 2003; Stokland et al., 2012). However, because of the centurylong intensive use of European forests, only a few patches of forest remain today that have been continuously present long enough to support fully developed saproxylic communities (Grove, 2002). The regional extinction of species with limited dispersal capabilities is typical in intensively managed forests with fragmented habitats (Kappes \& Topp, 2004).

If wood ceases to be extracted and forests are allowed to develop naturally, dead wood accumulates over time. However, many of the species that are locally extinct, especially those associated with stable microhabitats, typically have limited dispersal capabilities (Fayt et al., 2006; Buse, 2012). Forests with a recent accumulation of dead wood are inhabited by fewer red-listed species than forests in which dead wood has accumulated over a long period of time (Nilsson \& Baranowski, 1997). Furthermore, many rare saproxylics are affected both by substrate continuity and current substrate availability (Brunet \& Isacsson, 2009a). Saproxylic communities take a very long time to re-establish, even after forests cease to be exploited. The presence of both dead wood and saproxylic species is therefore considered indicative of high quality mature forest habitats (Alexander, 2004; Lassauce et al., 2011).

A decrease in dead wood is one of the biggest changes that occur in intensively managed forests (Ranius \& Fahrig, 2006). Studies and management practices for conserving saproxylic species are still mainly focused on the coarse woody material (see Davies et al., 2008 for a review). However, although frequently overlooked, small diameter wood debris also plays an important role as a substrate for saproxylic insects (Schiegg, 2001; Jonsell et al., 2007; Jonsell, 2008; Brin et al., 2011; Lassauce et al., 2012). For estimating the loss in biodiversity caused by current forest management, and the increase in biodiversity achieved by implementing restoration programs, standardized sampling protocols are required. They need to be suitable for sampling in many different habitats, and be cost effective. The "classical" methods of evaluating invertebrate biodiversity in forests involve periodical visits to traps set in the field (see for example Cerretti et al., 
2003; Hammond et al., 2004; Brunet \& Isacsson, 2009b; Sobek et al., 2009; Hardersen et al., 2012). However, these methods do not indicate the substrate in which the larvae developed, but only their presence. In situ eclector traps (e.g. Schiegg, 2001; Kappes \& Topp, 2004; Gibb et al., 2006) sample individual pieces of wood, but still require numerous visits to field sites. When resources are limited these methods cannot be used for large-scale monitoring of forests. For example, the Italian National Forest Inventory involves detailed measurements of wood and soil at thousands of randomly selected localities in forests in Italy (C.R.A. et al., 2008). The localities are often in areas that are not easily accessible. In addition, the standard protocol for the Inventory requires only a single visit to each site. Using "classical" methods to collect saproxylic insects is not possible in this context. However, saproxylic insects can be reared from dead wood in the laboratory (e.g. Hammond et al., 2004; Gedminas et al., 2007) and this requires only a single visit per sampling site.

Our study aimed to develop, test and optimize a simple and effective method of sampling saproxylic insects by rearing them from pieces of wood in the laboratory (i.e., the "grab-and-go" method). Despite Coleoptera being the most species-rich and well studied group of saproxylic insects (Bouget et al., 2008), to our knowledge no study on the saproxylic beetle coenosis associated with small diameter wood debris has been carried out in Italy. Furthermore, the saproxylic fauna of beech wood (Fagus sylvatica) has been rarely studied in detail in Italy (but see Cecchi \& Bartolozzi, 1997; Cerretti et al., 2003), whereas it is relatively well known in Central and Northern Europe (e.g. Derksen, 1941; Schiegg, 2001; Hövemeyer \& Schauermann, 2003; Kappes \& Topp, 2004; Bussler et al., 2005). We therefore focused on Coleoptera emerging from downed small and medium diameter decaying beech wood $(11 \pm 4 \mathrm{~cm}$ : DeWalt et al., 2003; Brin et al., 2011): this selection of wood was intended to maximize saproxylic species richness (Kappes \& Topp, 2004), being at the same time easily transportable. The specific aims of this research were:

To design, build and optimize the performance of ex situ emergence traps used to collect emerging beetles from downed small and medium diameter decaying beech wood.

To determine the minimum number of samples of wood necessary for a satisfactory description of the saproxylic beetle assemblage at a given site.

To investigate the association of the beetle assemblages with the physical characteristics of the wood.

The results of this study provide a guide for the future application of the "grab-and-go" method in the framework of large-scale monitoring of forests.

\section{MATERIAL AND METHODS}

\section{Sampling sites and collection and measurements of dead wood}

Samples of wood were collected in two beech forests with different structural and geographical features, and spaced $\sim 300$ $\mathrm{km}$ apart, so that the recommendations resulting from this study would be suitable for a broad range of localities. Between the end of April and the beginning of May 2011, we collected 100 samples of wood debris (diameter $11 \pm 4 \mathrm{~cm}$, length $50 \mathrm{~cm}$ ) lying on the forest floor, in structurally homogeneous areas in two Italian beech forests. The sites sampled were characterized by analyzing the structure of the two forests within the sampling areas. (1) Sega di Ala, Trento Province, Trentino-Alto Adige Region, NE Alps, henceforth referred to as TN (UTM WGS84: 32T 655709 5065142; $1400 \mathrm{~m}$ a.s.1.). Mixed young-mature beech forest with Fagus sylvatica (70\%), other broadleaved trees (20\%), and conifers $(10 \%)$. NW exposure, canopy cover $\sim 80 \%$. Density of wood debris suitable for this study: 3 pieces/ha. 50 samples collected on April 27. (2) Vallombrosa, Florence Province, Tuscany Region, NW Apennines, referred to as FI throughout this paper (UTM WGS84: 32T $7067654844223 ; 1270 \mathrm{~m}$ a.s.l.). Mature beech forest (100\% Fagus sylvatica). NW exposure, canopy cover $\sim 80 \%$. Wood debris suitable for this study: 5 pieces/ha. 50 samples collected on May 2.

Since saproxylic beetles tend to prefer the early and medium stages of wood decay (Alexander, 2002; Jonsson et al., 2005; Lassauce et al., 2012), and since the collected wood had to be transported intact to the rearing facility, we concentrated on collecting wood in decay class 2 and 3 (Hunter, 1990), and avoided class 1 (freshly fallen wood). Specifically, class 2 wood has loose bark and little sapwood degradation; class 3 wood has either traces of or no bark, and the initial stages of sapwood degradation $(<1 \mathrm{~cm}$ when tested with a knife). We cut a $50 \mathrm{~cm}$-long sample from each suitable piece of wood. The following variables for each sample of wood debris were recorded: (a) Maximum and minimum diameter, (b) Nodosity [(max diam-min diam)/mean diam], (c) Decay class according to Hunter (1990) (class 2: less than 10\% changed due to decay; class 3: decay percentage between 10 and 25\%); (d) Cortex cover (class 1: $>50 \%$; class 2 : 10-20\%; class 3: $<10 \%$ ); (e) Fungal hyphae ( $1=$ present, $0=$ absent $)$; (f) Lichens $(1=$ present, $0=$ absent); (g) Moisture content, determined as (weight at collection-dry weight)/(weight at collection). The dry weight was determined at the end of the rearing period, according to the standards set by UNI ISO 3130: 1985.

\section{Rearing protocol}

Since the sampling sites were visited only once, we collected the entomological samples using ex situ emergence traps. Each sample of wood was inserted in an emergence trap made of a non-toxic black PE pipe $(1.5 \mathrm{~cm}$ thick, $60 \mathrm{~cm}$ long, with an internal diameter of $26 \mathrm{~cm}$ ) (Fig. 1), certified for drinking water. Each pipe was closed at both ends by a dark $0.4 \mathrm{~mm}$ mesh screen. A white $250 \mathrm{ml}$ container, half filled with a saturated solution of water and $\mathrm{NaCl}$, was inserted into a hole in the underside of the pipe just behind the mesh screen. One drop of detergent was added to the solution in the container to diminish the surface tension. The opposite end of each pipe was shaded with a cardboard disk, to prevent light entering the pipe at that end. Upon emergence, saproxylic arthropods were attracted by the light coming through the white collecting container, eventually falling into the solution. Containers were collected once a week, from May 11 to September 28. During the course of this study, all the emergence traps were stored in a single room under a natural photoperiod, in a rearing facility in Verona (N Italy) (Fig. 1). At the end of the sampling season, all traps were carefully searched for dead individuals that had not fallen into the collecting containers. All Coleoptera collected were sorted to family level. Ptinidae were identified by G. Nardi, while those belonging to other families were sent to other specialists for species identification (see Acknowledgements). The collected material is preserved in $70 \%$ Ethanol, and stored at CNBFVR, Marmirolo (Mantua, Italy). 

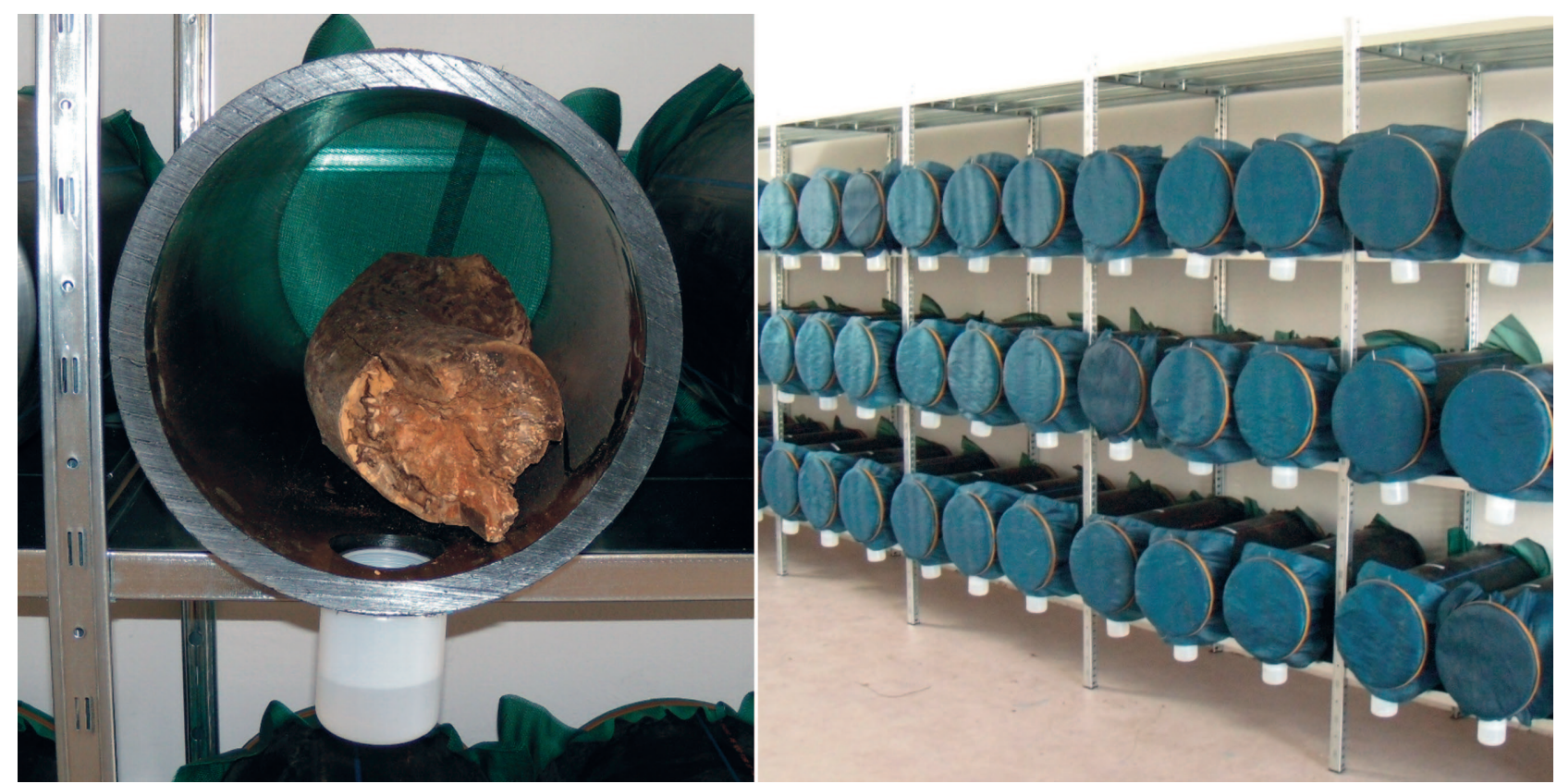

Fig. 1. Left: Ex situ emergence trap. The front screen has been removed to show interior. Right: Storage of the emergence traps used in this study.

\section{Analyses}

The minimum number of species living in the sections of wood collected in the two forests was determined using the species richness estimator ACE, computed using EstimateS 8.2.0. (Colwell, 2006). We used the same program to generate the rarefaction curves for species richness and the Shannon biodiversity index as functions of the number of sections of wood sampled. The curves were calculated separately for the two forests, each based on 1000 permutations.

To describe the association of species richness and diversity (dependent variables) with moisture content and mean diameter of wood samples (explanatory variables), and compare these trends between the two forests, we plotted these variables on scatterplots and then fitted the data with LOESS interpolations (99\% fitted points). These graphs were generated separately for the two forests.

To assess the variation in species richness and Shannon index (dependent variables) as a function of the class of wood decay and cortex cover, we fitted to the data General Linear Models including intercept, wood or cortex cover class, site, and the interaction between class and site. Prior to running the analyses, we inspected the normal probability plots in order to identify substantive departures from normality, and tested the assumption of homogeneity of variances using Levene's tests. When these tests returned a P-value below 0.05 (for the model including the effect of site, decay class, and their interaction on species richness), we used Mann-Whitney $U$ tests to assess the effect of site first, and then the effect of class separately in the two forests. Analyses were performed using PASW Statistics 18.0.0.

The multivariate ordination technique NMDS in Packet Vegan 2.0-0 (Oksanen et al., 2010) in R 2.13.2 was used to analyze the association between the parameters describing the samples of wood listed in Data Collection [(a)-(g)] and the structure of the saproxylic beetle coenosis. This analysis was based on a dissimilarity matrix computed using the zero-adjusted Bray-Curtis coefficent (Clarke et al., 2006). A 3-dimensional configuration was calculated both for the whole data set and for a selection of samples of wood of decay class 2, cortex cover $<50 \%$ (class
2 and 3), and mean diameter $=12 \pm 2 \mathrm{~cm}$. These features were chosen based on their association with beetle diversity (Shannon index) and species richness (see Results). NMDS analyses were conducted on (1) the data set including FI and TN, with sampling site treated as a variable, and (2) the data sets of the two sampling sites, separately. A non-parametric MANOVA (Anderson, 2001) implemented in Vegan (Oksanen et al., 2010) was used to assess whether beetle communities collected at the two sites were significantly different. This test uses zero-adjusted Bray-Curtis similarities (Clarke et al., 2006) and 999 permutations of the data matrix to determine significance.

\section{RESULTS}

We collected a total of 827 beetles, belonging to 54 species and to 21 families, from 100 samples of wood. The most common species were Ptilinus pectinicornis (Linnaeus, 1758) (Ptinidae) and Coxelus pictus (Sturm, 1807) (Zopheridae) (Table 1). Species richness, and estimated total species richness (ACE), were higher in FI (38/58 species) than in TN (27/30 species) (Table 1). The maximum number of beetles that emerged in one week was 120 for FI and 90 for TN (both in May). From June onwards, the number of beetles emerging declined markedly. After the middle of August, no more than one individual per week was collected: therefore, in this last period, Shannon index of 0 was recorded for each sampling occasion. Thirty three specimens (less than $4 \%$ of the total) were found dead inside the emergence traps at the end of the experiment. In the rarefaction curves (1000 permutations), the mean Shannon index increased steeply up to 15 samples of wood, and stabilized at around 20 samples, a trend common to both forests. The rarefaction curve of species richness was steeper for FI than for TN (Fig. 2).

For the samples from TN, the trends in Fig. 3 indicate a decrease in beetle diversity with increase in wood moisture, while moisture did not seem to be associated with 
TABLE 1. Specimens sampled, abundance, species richness, and minimum number of species estimated using the abundance-based richness estimator (ACE) (TN - Sega di Ala, NE Italian Alps; FI - Vallombrosa, NW Appennines). Species nomenclature follows Löbl \& Smetana (2004, 2006, 2007, 2008, 2011, 2011, 2012), omitting subgenera. Trophic guilds are reported as XYL - xylophagous, MYC - mycetophagous, PRED - predator, SAP SL - saproxylic sensu lato (Audisio et al., 2014). The conservation status is based on both the European and the Italian IUCN Red Lists of saproxylic beetles (Nieto \& Alexander, 2010; Audisio et al., 2014) (EU - Europe, IT - Italy, LC - Least Concern, NT - Near Threatened, EN - Endangered, DD - Data Deficient). Accidental captures - i.e., species that are not saproxylic sensu Speight (1989), are marked with an asterisk $(*)$ in the trophic guild column.

\begin{tabular}{|c|c|c|c|c|}
\hline \multirow{2}{*}{ Species } & \multirow{2}{*}{ Guild } & \multirow{2}{*}{ Conservation status } & \multicolumn{2}{|c|}{ No. specimens collected } \\
\hline & & & TN & FI \\
\hline \multicolumn{5}{|l|}{ Anthribidae } \\
\hline Phaenotherion $f$. fasciculatum Reitter, 1891 & XYL & LC IT & 0 & 2 \\
\hline Platystomos albinus (Linnaeus, 1758) & XYL & LC IT & 2 & 0 \\
\hline \multicolumn{5}{|l|}{ Cantharidae } \\
\hline Malthodes sp. & & & 0 & 1 \\
\hline \multicolumn{5}{|l|}{ Cerambycidae } \\
\hline Anaglyptus mysticus (Linnaeus, 1758) & XYL & LC EU, LC IT & 3 & 0 \\
\hline Leiopus n. nebulosus (Linnaeus, 1758) & XYL & LC IT & 5 & 0 \\
\hline Rhagium bifasciatum Fabricius, 1775 & XYL & LC IT & 1 & 0 \\
\hline Rutpela m. maculata (Poda von Neuhaus, 1761) & XYL & LC IT & 2 & 1 \\
\hline Stictoleptura s. scutellata (Fabricius, 1781) & XYL & NT IT & 0 & 2 \\
\hline Ciidae & & & & \\
\hline Cis bidentatus (A.G. Olivier, 1790) & MYC & LC IT & 2 & 0 \\
\hline Cis boleti (Scopoli, 1763) & MYC & LC IT & 3 & 0 \\
\hline Cis micans (Fabricius, 1792) & MYC & LC IT & 2 & 0 \\
\hline Orthocis alni (Gyllenhal, 1813) & MYC & LC IT & 0 & 12 \\
\hline Cleridae & & & & \\
\hline Opilo mollis (Linnaeus, 1758) & PRED & LC IT & 5 & 0 \\
\hline Tillus elongatus (Linnaeus, 1758) & PRED & NT IT & 0 & 19 \\
\hline Corylophidae & & & & \\
\hline ?Sericoderus lateralis (Gyllenhal, 1827) & PRED & & 1 & 0 \\
\hline Cryptophagidae & & & & \\
\hline Cryptophagidae gen. sp. & & & 0 & 1 \\
\hline Curculionidae & & & & \\
\hline Acalles lemur cisalpinus Stueben, 2003 & XYL & LC IT & 0 & 1 \\
\hline Echinodera hypocrita (Boheman, 1837) & XYL & LC IT & 2 & 0 \\
\hline Onyxacalles luigionii (A. \& F. Solari, 1907) & XYL & LC IT & 1 & 5 \\
\hline Orchestes fagi (Linnaeus, 1758) & * & & 1 & 0 \\
\hline Dasytidae & & & & \\
\hline Dasytes caeruleus (DeGeer, 1774) & PRED & LC IT & 2 & 39 \\
\hline Elateridae & & & & \\
\hline Denticollis rubens Piller \& Mitterpacher, 1783 & PRED & LC EU, NT IT & 2 & 1 \\
\hline Eucnemidae & & & & \\
\hline Hylis cariniceps (Reitter, 1902) & XYL & LC EU, NT IT & 0 & 7 \\
\hline Microrhagus pygmaeus (Fabricius, 1792) & XYL & DD EU, NT IT & 6 & 0 \\
\hline Latridiidae & & & & \\
\hline Dienerella vincenti Johnson, 2007 & MYC & DD IT & 0 & 2 \\
\hline Stephostethus alternans (Mannerheim, 1844) & MYC & LC IT & 1 & 0 \\
\hline Leiodidae & & & & \\
\hline Leiodinae gen. sp. & MYC & & 0 & 1 \\
\hline Melandryidae & & & & \\
\hline Conopalpus testaceus (A.G. Olivier, 1790) & MYC & NT IT & 0 & 7 \\
\hline Orchesia undulata Kraatz, 1853 & MYC & LC IT & 7 & 3 \\
\hline Monotomidae & & & & \\
\hline Rhizophagus bipustulatus (Fabricius, 1792) & MYC & LC IT & 0 & 10 \\
\hline Rhizophagus dispar (Paykull, 1800) & MYC & LC IT & 0 & 7 \\
\hline Ptiliidae & & & & \\
\hline Ptenidium sp. n. Sörensson & & & 0 & 3 \\
\hline Ptinidae & & & & \\
\hline Grynobius planus (Fabricius, 1787) & XYL & LC IT & 43 & 0 \\
\hline Hemicoelus costatus (Aragona, 1980) & XYL & LC IT & 40 & 25 \\
\hline Ptilinus pectinicornis (Linnaeus, 1758) & XYL & LC IT & 95 & 105 \\
\hline Ptinomorphus imperialis (Linnaeus, 1767) & XYL & LC IT & 2 & 0 \\
\hline Stegobium paniceum (Linnaeus, 1758) & $*$ & & 0 & 1 \\
\hline Scraptiidae & & & & \\
\hline Anaspis ruficollis (Fabricius, 1792) & XYL & EN IT & 5 & 3 \\
\hline Scydmaenidae & & & & \\
\hline Cephennium simile Reitter, 1882 & PRED & & 0 & 1 \\
\hline Cephennium tarsale Holdhaus, 1905 & PRED & & 0 & 1 \\
\hline Staphylinidae & & & & \\
\hline Acrulia inflata (Gyllenhal, 1813) & PRED & NT IT & 0 & 19 \\
\hline Bibloporus bicolor devillei Jeannel, 1950 & PRED & NT IT & 0 & 11 \\
\hline Bolitochara obliqua Erichson, 1837 & SAP SL & LC IT & 0 & 6 \\
\hline Bryaxis puncticollis (Denny, 1825) & PRED & LC IT & 1 & 0 \\
\hline Dasycerus sulcatus Brongniart, 1800 & MYC & LC IT & 0 & 1 \\
\hline Dropephylla sp. & & & 0 & 1 \\
\hline Euplectus sp. & & & 0 & 1 \\
\hline Leptusa apennina Holdhaus, 1924 & SAP SL & & 0 & 3 \\
\hline Leptusa fumida (Erichson, 1839) & SAP SL & LC IT & 4 & 79 \\
\hline Leptusa pulchella (Mannerheim, 1830) & SAP SL & LC IT & 3 & 32 \\
\hline Leptusa ruficollis (Erichson, 1839) & SAP SL & LC IT & 0 & 41 \\
\hline Plectophloeus fischeri (Aubé, 1833) & PRED & LC IT & 0 & 1 \\
\hline Zopheridae & & & & \\
\hline Colydium elongatum (Fabricius, 1787) & PRED & LC IT & 0 & 1 \\
\hline Coxelus pictus (Sturm, 1807) & XYL & LC IT & 74 & 56 \\
\hline Abundance (Total) & & & 315 & 512 \\
\hline Species richness (Total) & & & 27 & 38 \\
\hline Min. estimated species richness (ACE) & & & 30 & 58 \\
\hline
\end{tabular}



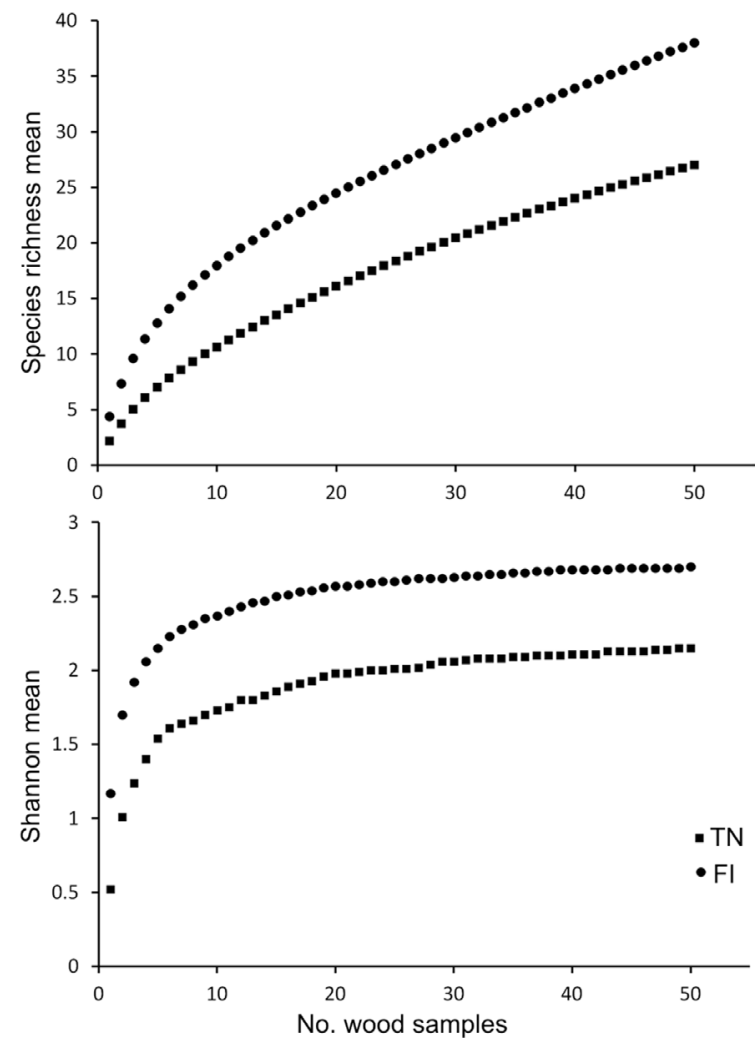

Fig. 2. Rarefaction curves for species richness (top panel) and Shannon index (bottom panel) as a function of the number of samples of wood collected in the two beech forests (TN - Sega di Ala, NE Italian Alps; FI - Vallombrosa, NW Appennines).

species richness. As for the samples from FI, on the other hand, species richness remained constant between 0 and $40 \%$ moisture, above which it decreased. Furthermore, Shannon index increased to a greater extent over the range in moisture of $0-40 \%$ than of $40-60 \%$. Species richness and diversity at both sites were positively associated with the mean diameter of the samples of wood. However, for diameters under $10 \mathrm{~cm}$, the Shannon index values for samples from TN were frequently close to 0 (Fig. 3).

When considering the whole sample, the NMDS (stress $=0.145$ ) indicated four factors significantly associated with the structuring of the saproxylic beetle cenosis: mean diameter $(P<0.01)$, moisture $(P<0.01)$, sampling site $(P<0.01)$ and decay class $(P<0.01)$ (Fig. 4$)$. The nonparametric MANOVA indicated that the beetle communities in TN and FI differed significantly $\left(\mathrm{F}_{1,98}=8.173, P<\right.$ $0.001)$. When the samples collected in the two forests were analyzed separately, maximum diameter and decay class were significantly associated with the beetle coenosis in FI $(P<0.05)$. In TN, the significant factors were minimum and mean diameter, and weight $(P<0.05)$.

The boxplots of species richness and diversity (Shannon index) expressed as a function of cortex cover and decay class are presented in Fig. 5. Both species richness and diversity differed significantly at the two sites $(P<0.01)$, with FI being consistently richer and more diverse than TN. Both richness and diversity did not differ significantly in decay class 2 and 3 ( $P>0.05$ in all cases). However,
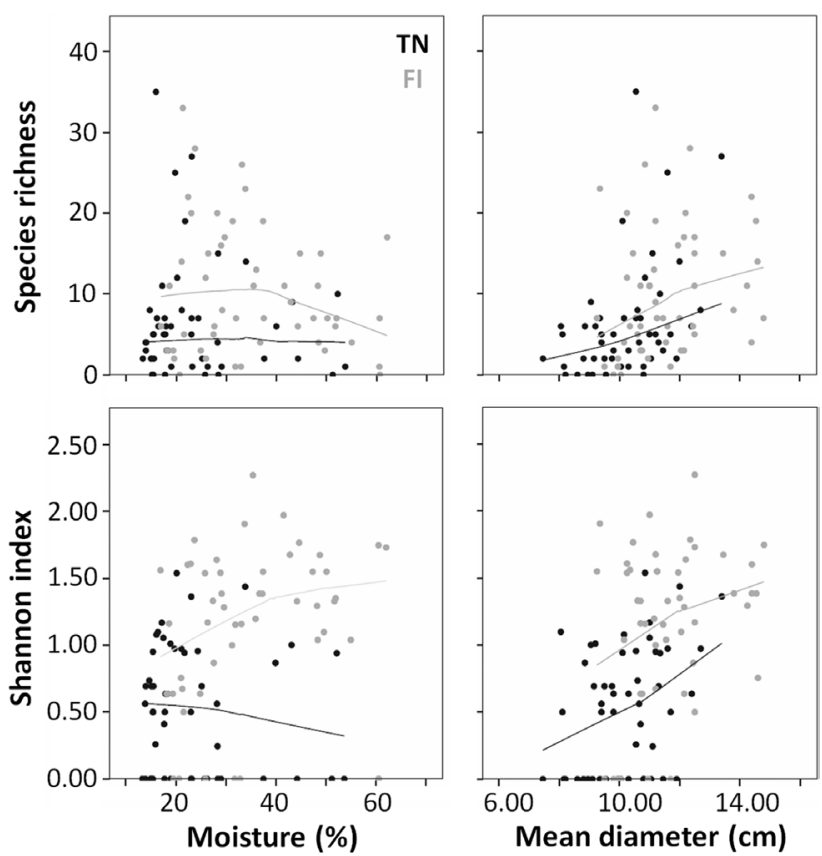

Fig. 3. Scatterplots of saproxylic species richness and diversity (Shannon index) as a function of moisture and mean diameter of samples of wood. Grey dots - FI, black dots - TN. Trend lines were obtained using LOESS interpolation ( $99 \%$ fitted points).

the variance in species richness recorded for decay class 3 was lower than for class 2 (Levene's test: $P=0.018$ ), and the Shannon index was 0 more frequently for class 3 than class 2 . In TN, the Shannon index was significantly associated with cortex cover. In particular, a lower diversity was recorded for the samples with $>50 \%$ cortex cover (class 1 ) than for classes 2 and 3 (LSD post-hoc tests: class 1-class $2, P<0.05$; class 1 -class $3, P<0.05$; class 2 -class $3, P>$ $0.05)$.

Based on the above analysis of the association of the features of the wood with beetle diversity and species richness, we further analyzed a sub-sample of wood with a decay class $=2$, cortex cover class $=2$ and 3 and mean diameter $=12 \pm 2 \mathrm{~cm}$. The NMDS of this sub-sample (stress $=0.142$ ) separated the two forests more markedly (Fig. 4), and the non-parametric MANOVA also indicated a significant difference $\left(\mathrm{F}_{1,37}=4.356, P=0.002\right)$. The relative variance explained was $10.53 \%$, as opposed to $7.70 \%$ when all samples were included in the analysis. In addition, for these sub-samples moisture was a significant factor $(P=$ 0.05 ) (Fig. 4). When the samples collected in the two forests were analyzed separately, the only parameter significantly associated with the saproxylic beetle coenosis was nodosity in TN $(P=0.02)$.

\section{DISCUSSION}

Our method focused on a rather narrow selection of dead wood, excluding a wide range of microhabitats that saproxylic beetles colonize (Alexander 2002; Bussler et al., 2005, Stokland et al., 2012). Most substrates which are known to sustain rich communities of saproxylic beetles (Alexander, 2002; Bussler et al., 2005) were not sampled. The species richness recorded in the wood sampled was 

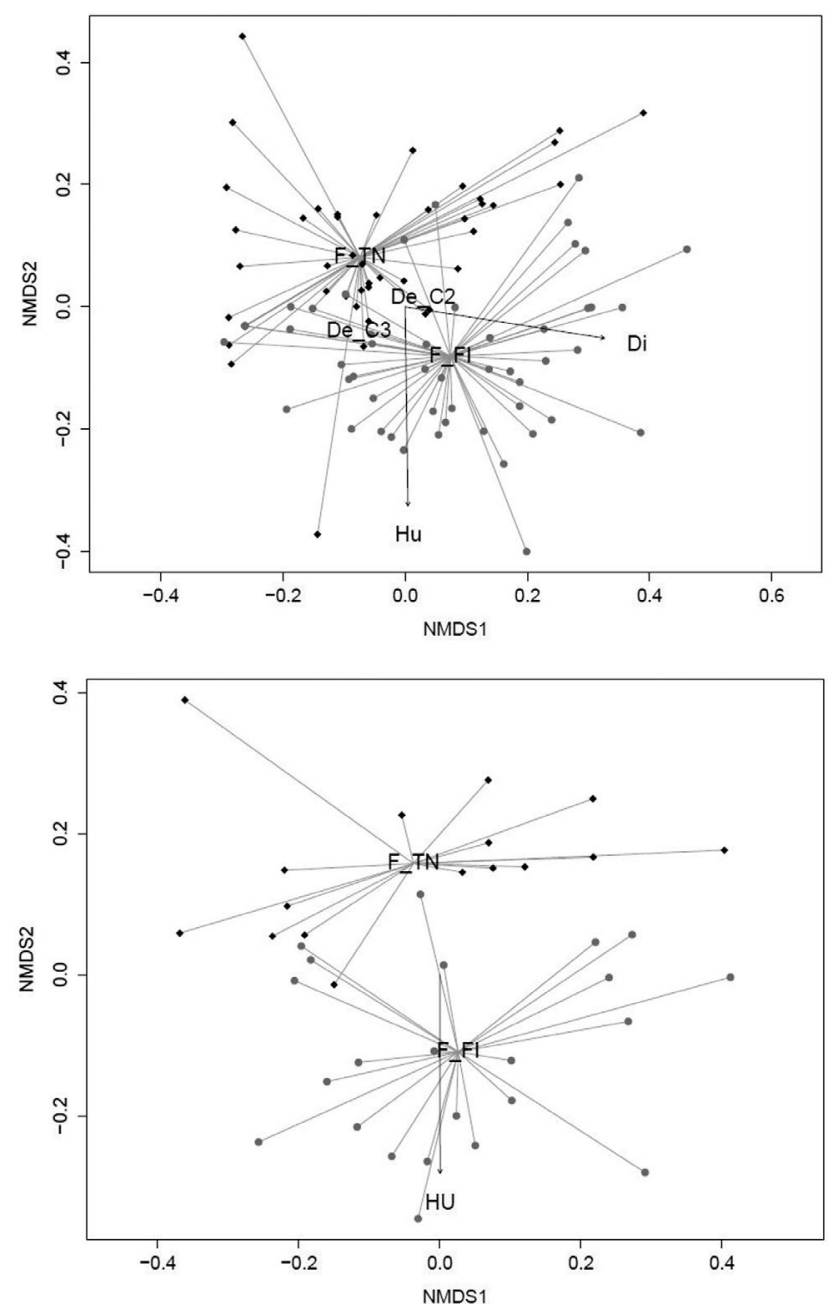

Fig. 4. NMDS (top panel) of the entire data set and (bottom panel) of a selection of wood debris of decay class $=2$ (less than $10 \%$ changed due to decay), cortex cover class $=2(10-50 \%)$ and $3(<10 \%)$, and mean diameter $=12 \pm 2 \mathrm{~cm}$. The centroids for the two sampling sites (F_TN - Sega di Ala, NE Italian Alps; F_FI - Vallombrosa, NW Appennines) are reported. The relative variance explained by site was $7.70 \%$ when all samples were considered, and increased to $10.53 \%$ for the selected sub-set of samples of wood. F - forest, Di - mean diameter, De - decay class, Hu - moisture.

nonetheless remarkable. From one hundred samples of small and medium diameter dead wood collected in two beech forests (one in the Apennines and one in the Alps), 827 saproxylic beetles emerged, belonging to 54 species and 21 families. Statistical inference allowed us to estimate the presence of at least 58 saproxylic beetle species in FI (Appennines), and at least 30 in TN (Alps). The higher species richness in FI might be related to the greater maturity of that forest and the larger quantity of dead wood present. In addition, FI is located south of TN and at a lower altitude, and has a warmer climate than TN. Similarly, in Sweden, the saproxylic beetle fauna is richer in lowland than in upland beech forests (Brunet \& Isacsson, 2010). In northern and central Europe, small and medium diameter wood debris is an important substrate for saproxylic insects (Schiegg, 2001; Kappes \& Topp, 2004; Jonsell et al., 2007;

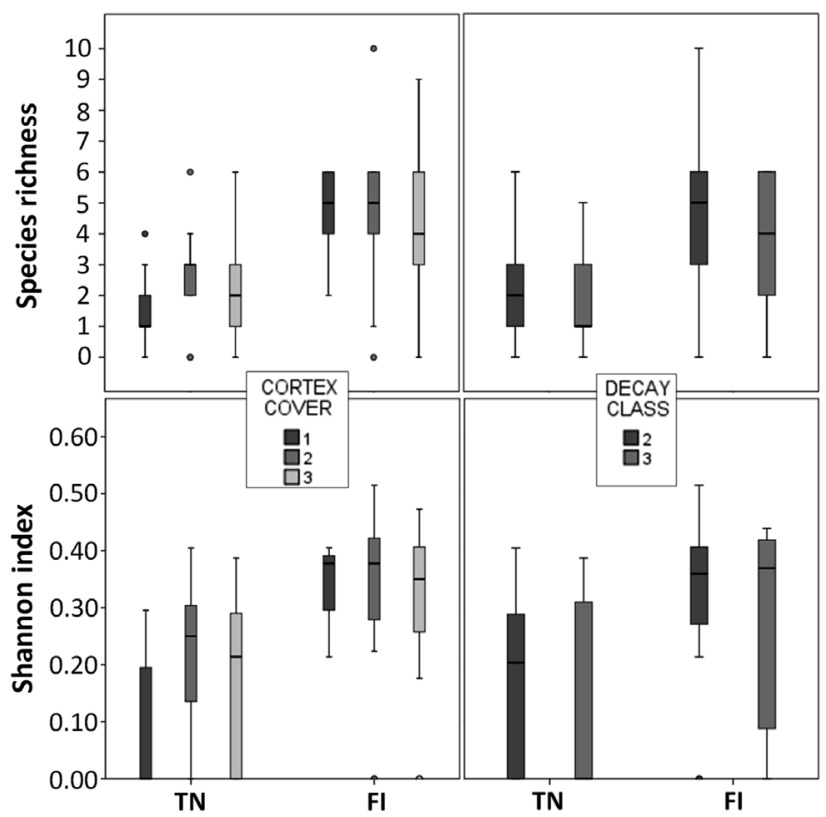

Fig. 5. Boxplots of species richness and diversity of saproxylic beetles (Shannon index) in TN and FI as a function of cortex cover class $(1>50 \% ; 2=10-50 \% ; 3<10 \%)$ (panels on the left) and decay class (class 2: less than $10 \%$ changed due to decay; class 3 : decay percentage between 10 and $25 \%$ - Hunter, 1990) (panels on the right). Shannon index is plotted on a logarithmic scale.

Jonsell, 2008). In beech woods, medium size dead wood yields the highest number of species per sample, compared with that with diameters of 6-7 cm and 40-60 cm (Kappes $\&$ Topp, 2004). In addition, branches with a diameter of 5-20 cm sustain species that are not present in wood with a larger diameter (Harz \& Topp, 1999; Schiegg 2001; Kappes \& Topp, 2004). Combined with previous findings (see also Brin et al., 2011), our results suggest that removing small and medium diameter wood debris from forests (a common practice in Italy, where it is mainly used as firewood) has a negative effect on forest biodiversity.

Previous studies indicate that excessively humid substrates are not suitable for some xylophagous larvae (Hanks et al., 1999; Ueda \& Shibata, 2007; Ols et al., 2013). Interestingly, our results indicated a decrease in beetle diversity with increasing wood moisture only in TN, while diversity actually increased with wood moisture in FI. However, this trend was accompanied by a decrease in species richness beyond $40 \%$ moisture content, supporting the idea that moist wood sustains a few abundant species at this latter site. The importance of humidity in structuring the beetle coenosis was also highlighted by our NMDS analysis (Fig. 4).

Wood debris size and saproxylic assemblage diversity are usually positively associated (Ranius \& Jansson, 2000; Dahlberg \& Stokland, 2004; Jonsell et al., 2007; Lassauce et al., 2012) and, despite the narrow range of wood diameters sampled $(11 \pm 4 \mathrm{~cm})$, in our study we detected an increase in species richness and diversity with increasing wood diameter. Decay class and presence of bark are both correlated with the length of time the wood has been dead and decaying (Hunter, 1990). Different decay stages sus- 
tain different saproxylic assemblages (Grove, 2002), and saproxylic beetles generally favor the early and medium stages (Alexander, 2002; Jonsson et al., 2005; Lassauce et al., 2011, 2012). However, Kappes \& Topp (2004) reported that the stage of decay does not influence overall species richness. For our wood samples, there were no significant differences in diversity and species richness between Hunter's (1990) class 2 and class 3. However, in class 2 the Shannon index was 0 less often than in class 3 . As for presence of bark, our analysis indicated that, at least in TN, saproxylic beetles favored decaying wood with residual cortex cover $<50 \%$. Overall, these results indicate that the highest saproxylic beetle diversity and species richness occurs in late class 2 wood, which has little or no residual cortex.

The features of the wood associated with the structure of saproxylic beetle assemblages differed in the two forests. Specifically, maximum diameter and decay class were significant in FI, whereas minimum and mean diameter and weight were significant in TN. When analyzed together, the beetle assemblages in the two forests were significantly different. This was expected, as the sites selected had different structural and geographical features (see Materials and Methods), which are known to influence species composition (Minelli et al., 2002; Brunet \& Isacsson, 2010). Since this study aimed to develop, test and optimize a method for sampling and comparing saproxylic beetle assemblages, it was important to minimize the intra-site variability of the wood collected. To achieve this goal, and to provide a high level of diversity in the wood sampled, we selected a subsample of class 2 wood, with a diameter of $12 \pm 2 \mathrm{~cm}$ and cortex cover $<50 \%$. When this data set was analyzed, the assemblages in to the two forests overlapped less than when the whole data set was analyzed.

The ex situ emergence traps used in this study proved efficient and effective in collecting saproxylic beetles. Less than $4 \%$ of the total sample failed to enter the collecting containers and were found dead inside the traps at the end of the sampling season. Nearly all the individuals collected could be classified as saproxylic sensu Speight (1989), with only two exceptions: one "Beech Leaf-Mining Weevil" Orchestes fagi (Curculionidae) collected in TN, and one "Bread Beetle" Stegobium paniceum (Ptinidae) collected in FI. The most abundant species collected colonize either weakened trees and recently fallen and decaying wood (Ptilinus pectinicornis), or markedly decayed wood (Coxelus pictus). Several of the species collected are listed in the Italian IUCN Red List of Saproxylic Beetles (Audisio et al., 2014), including eight classified as likely to become endangered in the near future (NT), one at high risk of extinction (EN), and one for which not enough data are available to make an assessment of its risk of extinction (DD). FI appeared to be the site of greatest conservation interest, with nine species included in categories with higher conservation ranks than Least Concern compared to three in TN. Furthermore, one species of Ptiliidae new to science is currently being described by M. Sörensson based on material collected in FI (Table 1).

\section{Use of the "grab-and-go" method in large-scale forest monitoring programs}

Beech forests are often considered to be low biodiversity habitats compared with other forest types (Carpaneto, 2006; Lassauce et al., 2012), and beech dead wood supports a lower number of species than that of oak (Kappes $\&$ Topp 2004). Nevertheless, the dead wood we collected in this study sustained well-structured saproxylic beetle assemblages at both sites. This observation has both practical and theoretical implications. On one hand, downed small and medium diameter dead wood should be given greater consideration when planning conservation measures for saproxylic organisms. On the other hand, given the ease of sampling, the validity of the fraction of wood debris used in this study needs to be tested as an indicator of sustainable forest management (Similä et al., 2006; Maleque et al., 2009).

The relative ease of finding and transporting small diameter wood samples makes our "grab-and-go" method suitable for large-scale forest monitoring programs. This method requires only a single visit to each site, and can therefore be used to sample areas that cannot be reached easily. A further advantage is that the fieldwork can be carried out by technicians without specific entomological training. In our study, the rarefaction curves of species richness did not reach an asymptote at either site, as expected in invertebrate assemblages (Gotelli \& Colwell, 2001). However, in both cases these curves became less steep around fifteen samples of wood. Furthermore, the rarefaction curves of Shannon index indicate that twenty samples of wood provided a satisfactory description of the saproxylic beetle diversity at both sites considered in this study. Based on these results, at least twenty $50 \mathrm{~cm}$-long samples of wood should be collected at each site for a good estimate of biodiversity. The collection of wood should be carried out immediately after the snow has melted (between the end of March and the beginning of May in Italy), and saproxylic beetles should be collected using emergence traps up to the end of July, when the detectable biodiversity becomes too low to allow statistical comparisons. To minimize intra-site variability, and maximize the likelihood of detecting intersite differences, collecting should focus on class 2 wood, with a diameter of $12 \pm 2 \mathrm{~cm}$, and $<50 \%$ of cortex cover. Furthermore, it is advisable to choose downed wood lying on top of the litter, rather than embedded in it. This will ensure that the moisture content of the collected wood is comparatively low: an important aspect, as high water content has a negative effect on species richness (Hanks et al., 1999; Ueda \& Shibata, 2007; Ols et al., 2013).

Emergence traps are among the most reliable tools for sampling the saproxylic fauna because they mainly collect saproxylic species, avoiding accidental captures of non-saproxylic ones (Økland, 1996; Wikars et al., 2005; Alinvi et al., 2007; Jonsell, 2008). Possible drawbacks of using the "grab-and-go" method in large-scale monitoring programs include the need for large rearing facilities, and dependence on taxonomists for the identification of numerous specimens. The latter is common to all sampling 
methods for invertebrates, and cannot be avoided easily, as the use of parataxonomy (e.g. morphospecies) has resulted in severe flaws in ecological and conservation studies (Krell, 2004). However, since the "grab-and-go" method yields smaller samples than other standard methods (pers. obs.), its use in large-scale forest monitoring programs should keep sample size manageable, and therefore reduce the costs of sorting and taxonomic expertise dramatically. A further study has been ongoing to compare the results obtained using the "grab-and-go" method presented here with those obtained using window and Malaise traps at several sites. The future use of the "grab-and-go" method at a large scale could also help in evaluating the effectiveness of specific management policies based on the conservation value of the communities sampled at multiple sites (Tropek et al., 2013). However, it is likely that the conservation value of individual sites will be underestimated if site assessments are exclusively based on this method, because the most species-rich substrates will not be sampled. In this framework, the "grab-and-go" method should serve as a first screening. More detailed analyses should then be performed with specific techniques for the study of endangered saproxylics at selected sites.

ACKNOWLEDGEMENTS. This study (project ref.: "Assessment of forest biodiversity by means of saproxylic arthropods") was carried out within the framework of the National Forest and Carbon Sink Inventory (INFC), and sponsored by the grant no. 28024/03/2011, National Forest Service, Service II, Division VI, Rome (Enrico Pompei, CFS-SIAT, Rome, Italy). P. Gasperini (CRA-MPF, Trento, Italy) contributed important statistical information within the framework of the INFC. We are indebted to all the specialists who volunteered to identify the specimens collected: P. Audisio (Corylophidae, Monotomidae, Zopheridae), G. Castellini (Scydmaenidae), P. Cornacchia (Anthribidae, Cerambycidae, Cleridae), G. Liberti (Cantharidae, Dasytidae), L. Leseigneur (Eucnemidae), M. Meregalli (Curculionidae), N. Nikitsky (Melandryidae), G. Platia (Elateridae), R. Poggi (Staphylinidae: Pselaphinae), J. Reibnitz (Ciidae), W. Rücker (Latridiidae), E. Ruzzier (Scraptiidae), M. Sörensson (Ptiliidae), and A. Zanetti (Staphylinidae, Pselaphinae excepted). Thanks are also due to G. Gorga and A. Morani for their help with fieldwork; to V. Aguiar Alves Dorini, E. Mitali, F. Rossato, and G. Scaglioni for assistance in sorting the entomological material; to M. Ascari, O. Conti, S. Delpero, L. Fedrigoli, F. Mazzocchi, S. Valerio, and F. Zomer for their support with logistics; and to M. Konvička, S. Chiari, and two anonymous reviewers for their constructive comments on a previous version of this manuscript.

\section{REFERENCES}

AleXander K.N.A. 2002: The Invertebrates of Living and Decaying Timber in Britain \& Ireland. A Provisional Annotated Checklist. Engl. Nat. Res. Rep. No. 467. English Nature, Peterborough, $142 \mathrm{pp}$.

AlEXANDER K.N.A. 2004: Revision of the index of ecological continuity as used for saproxylic beetles. Engl. Nat. Res. Rep. No. 574. English Nature, Peterborough, $61 \mathrm{pp}$.

Alinvi O., Ball J.P., Danell K., Huältén J. \& Pettersson R.B. 2007: Sampling saproxylic beetle assemblages in dead wood logs: comparing window and eclector traps to traditional bark sieving and a refinement. - J. Insect Conserv. 11: 99-112.
ANDERSOn M.J. 2001: A new method for non-parametric multivariate analysis of variance. - Austral. Ecol. 26: 32-46.

Audisio P., Baviera C., Carpaneto G.M., Biscaccianti A.B., Battistoni A., Teofili C. \& Rondinini C. (eds) 2014: Lista Rossa IUCN dei Coleotteri Saproxilici Italiani. Comitato Italiano IUCN e Ministero dell'Ambiente e della Tutela del Territorio e del Mare, Roma, $134 \mathrm{pp}$.

Bouget C., Brustel H. \& Zagatti P. 2008: The French Information System on Saproxylic Beetle Ecology (FRISBEE): an ecological and taxonomical database to help with the assessment of forest conservation status. - Rev. Ecol. (Terre Vie) 63: $25-28$.

Brin A., Bouget C., Brustel H. \& Jactel H. 2011: Diameter of downed woody debris does matter for saproxylic beetle assemblages in temperate oak and pine forests. - J. Insect Conserv. 15: 653-669.

BRUNET J. \& IsACSSON G. 2009a: Restoration of beech forest for saproxylic beetles - effects of habitat fragmentation and substrate density on species diversity and distribution. - Biodiv. Conserv. 18: 2387-2404.

BRUNET J. \& ISACSSON G. 2009b: Influence of snag characteristics on saproxylic beetle assemblages in a south Swedish beech forest. - J. Insect Conserv. 13: 515-528.

Brunet J. \& Isacsson G. 2010: A comparison of the saproxylic beetle fauna between lowland and upland beech forests in southern Sweden. - Ecol. Bull. 53: 131-139.

BUSE J. 2012: "Ghosts of the past": flightless saproxylic weevils (Coleoptera: Curculionidae) are relict species in ancient woodlands. - J. Insect Conserv. 16: 93-102.

Bussler H., Müller J. \& Dorka V. 2005: European natural heritage: the saproxylic beetles in the proposed Parcul National Defileul Jiului. - Anale ICAS 48: 3-19.

Carpaneto G. 2006: Aspetti faunistici. In Minelli A. (ed.): Le Faggete Appenniniche. Avanguardie e Relitti di Foresta Continentale. Quaderni Habitat n. 15. Ministero dell'Ambiente e della Tutela del Territorio e del Mare and Museo Friulano di Storia Naturale, Udine, pp. 71-126.

Cavalli R. \& Mason F. (eds) 2003: Techniques for Re-establishment of Dead Wood for Saproxylic Fauna Conservation. LIFE Nature Project NAT/IT/99/6245 Bosco della Fontana (Mantova, Italy). G. Arcari, Mantova, $56 \mathrm{pp}$.

Cecchi B. \& BARtolozzi L. 1997: I coleotteri xilofagi e subcorticicoli del Parco Nazionale delle Foreste Casentinesi, Monte Falterona e Campigna (Insecta: Coleoptera). - Boll. Soc. Entomol. Ital. 29: 119-139.

Cerretti P., Tagliapietra A., Tisato M., Vanin S., Mason F. \& Zapparoli M. (eDs) 2003: Artropodi dell'Orizzonte del Faggio nell'Appennino Settentrionale, Primo Contributo. Conservazione Habitat Invertebrati 2. G. Arcari, Mantova, 253 pp.

Clarke K.R., Somerfield P.J. \& Chapman M.G. 2006: On resemblance measures for ecological studies, including taxonomic dissimilarities and a zero-adjusted Bray-Curtis coefficient for denuded assemblages. - J. Exp. Mar. Biol. 330: 55-80.

Colwell R.K. 2006: EstimateS: Statistical Estimation of Species Richness and Shared Species from Samples. Version 8.0.0. http://purl.oclc.org/estimates. Accessed 12 January 2012.

C.R.A., F.E.M. \& C.F.S. 2008: Inventario Nazionale delle Foreste e dei Serbatoi Forestali di Carbonio INFC. Manuale di Campagna per il Rilievo degli Attributi Integrativi (Fase 3+). Ministero delle Politiche Agricole, Alimentari e Forestali, Roma, 114 pp.

Dahlberg A. \& Stokland J. 2004: Vedlevande arters krav på substrat - en sammanställning och analys av 3600 arter. [Substrate Requirements of Wood-inhabiting Species - a Synthesis 
and Analysis of 3600 Species.] Skogsstyrelsen, Jönköping, 70 pp. [in Swedish, English abstr.].

Davies Z.G., Tyler C., Stewart G.B. \& Pullin A.S. 2008: Are current management recommendations for conserving saproxylic invertebrates effective? - Biodiv. Conserv. 17: 209-234.

DERKSEN W. 1941: Die Succession der pterygoten Insekten im abgestorbenen Buchenholz. - Z. Morphol. Oekol. Geogr. Tiere 37: 683-734.

DeWalt S.J., Maliakala S.K. \& Denslow J.S. 2003: Changes in vegetation structure and composition along a tropical forest chronosequence: implications for wildlife. - Forest Ecol. Manag. 182: 139-151.

Fayt P., Dufrêne M., Branquart E., Hastir P., Pontégnie C., Henin J.M. \& VersteIRT V. 2006: Contrasting responses of saproxylic insects to focal habitat resources: the example of longhorn beetles and hoverflies in belgian deciduous forests. $-J$. Insect Conserv. 10: 129-150.

Gedminas A., Lynikiene J. \& Zeniauskas R. 2007: Cambioxylofauna abundance and species diversity of cutting residues in Scots pine and Norway spruce clear-cuts in Lithuania. Biomass Bioenergy 31: 733-738.

Gibb H., HJältén J., Ball J.P., Atlegrim O., Pettersson R.B., Hilszczanski J., Johansson T. \& Danell K. 2006: Effects of landscape composition and substrate availability on saproxylic beetles in boreal forests: a study using experimental logs to monitor assemblages. - Ecography 21: 191-204.

Gotelli N.J. \& Colwell R.K. 2001: Quantifying biodiversity: procedures and pitfalls in the measurement and comparison of species richness. - Ecol. Lett. 4: 379-391.

Grove S.J. 2002: Saproxylic insect ecology and the sustainable management of forests. - Annu. Rev. Ecol. Syst. 33: 1-23.

Hammond H.E.J., Langor D.W. \& Spence J.R. 2004: Saproxylic beetles (Coleoptera) using Populus in boreal aspen stands of western Canada: spatiotemporal variation and conservation of assemblages. - Can. J. Forest Res. 34: 1-19.

Hanks L.M., Paine T.D., Millar J.G., Campbell C.D. \& Schuch U.K. 1999: Water relations of host tree and resistance to the phloem-boring beetle Phoracantha semipunctata F. (Coleoptera: Cerambycidae). — Oecologia 119: 400-407.

Hardersen S., Toni I., Cornacchia P., Curletti G., Leo P., Nardi G., Penati F., Piattella E. \& Platia G. 2012: Survey of selected beetle families in a floodplain remnant in northern Italy. - Bull. Insectol. 65: 199-205.

Harz B. \& Topp W. 1999: Dead wood in commercial forest: a source of danger for the outbreak of pest species? - Forstwiss. Zentralbl. 118: 302-313.

Hövemeyer K. \& Schauermann J. 2003: Succession of Diptera on dead beech wood: A 10-year study. — Pedobiologia 47: 61-75.

HunTer M.L. 1990: Wildlife, Forests and Forestry. Prentice Hall, Englewood Cliffs, NJ, 370 pp.

JoNSELL M. 2008: Saproxylic beetle species in logging residues: which are they and which residues do they use? - Norw. J. Entomol. 55: 109-122.

Jonsell M., Hansson J. \& Wedmon L. 2007: Diversity of saproxylic beetle species in logging residues in Sweden - comparisons between tree species and diameters. - Biol. Conserv. 138: 89-99.

Jonsson B.G., Kruys N. \& Ranius T. 2005: Ecology of species living on dead wood - lessons for dead wood management. Silva Fenn. 39: 289-309.

Kappes H. \& Topp W. 2004: Coleoptera from dead wood in a managed broadleaved forest in Central Europe. - Biodiv. Conserv. 13: $1905-1924$.
KRELL F.T. 2004: Parataxonomy vs. taxonomy in biodiversity studies - pitfalls and applicability of 'morphospecies' sorting. - Biodiv. Conserv. 13: 795-812.

Lassauce A., Paillet Y., Jactel H. \& Bouget C. 2011: Dead wood as a surrogate for forest biodiversity: Meta-analysis of correlations between dead wood volume and species richness of saproxylic organisms. - Ecol. Indic. 11: 1027-1039.

Lassauce A., Lieutier F. \& Bouget C. 2012: Woodfuel harvesting and biodiversity conservation in temperate forests: Effects of logging residue characteristics on saproxylic beetle assemblages. - Biol. Conserv. 147: 204-212.

LöBl I. \& Smetana A. (eds) 2004: Catalogue of Palaearctic Coleoptera. Vol. 2. Hydrophiloidea - Histeroidea - Staphylinoidea. Apollo Books, Stenstrup, 942 pp.

LöBl I. \& Smetana A. (eds) 2006: Catalogue of Palaearctic Coleoptera. Vol. 3. Scarabaeoidea, Scirtoidea, Dascilloidea, Buprestoidea, Byrrhoidea. Apollo Books, Stenstrup, 690 pp.

LöBl I. \& Smetana A. (eds) 2007: Catalogue of Palaearctic Coleoptera. Vol. 4. Elateroidea, Derodontoidea, Bostrichoidea, Lymexyloidea, Cleroidea, Cucujoidea. Apollo Books, Stenstrup, $935 \mathrm{pp}$.

Löbl I. \& Smetana A. (eds) 2008: Catalogue of Palaearctic Coleoptera. Vol. 5. Tenebrionoidea. Apollo Books, Stenstrup, 670 $\mathrm{pp}$

Löbl I. \& Smetana A. (eds) 2010: Catalogue of Palaearctic Coleoptera. Vol. 6. Chrysomeloidea. Apollo Books, Stenstrup, 924 pp.

LöBl I. \& Smetana A. (eds) 2011: Catalogue of Palaearctic Coleoptera. Vol. 7. Curculionoidea I. Apollo Books, Stenstrup $373 \mathrm{pp}$.

LöBl I. \& Smetana A. (eds) 2012: Catalogue of Palaearctic Coleoptera. Vol. 8. Curculionoidea II. Apollo Books, Stenstrup, $700 \mathrm{pp}$.

Maleque M.A., Maeto K. \& IshiI H.T. 2009: Arthropods as bioindicators of sustainable forest management, with a focus on plantation forests. - Appl. Entomol. Zool. 44: 1-11.

Minelli A., Chemini C., Argano R. \& Ruffo S. 2002: La Fauna in Italia. Touring, Milano and Ministero dell'Ambiente e della Tutela del Territorio, Roma, $448 \mathrm{pp}$

Nieto A. \& AleXander K.N.A. 2010: European Red List of Saproxylic Beetles. Publications Office of the European Union, Luxembourg, $56 \mathrm{pp}$.

NiLSSON S.G. \& BARANOWSKI R. 1997: Habitat predictability and the occurrence of wood beetles in old-growth beech forests. Ecography 20: 491-498.

ØKLAND B. 1996: A comparison of three methods of trapping saproxylic beetles. - Eur. J. Entomol. 93: 195-209.

Oksanen J., Blanchet F.G., Kindt R., Legendre P., Minchin P.R., O’Hara R.B., Simpson G.L., Solymos P., Stevens M.H.H. \& Wagner H. 2010: vegan: Community Ecology Package. http:// cran.r-project.org/web/packages/vegan/index.html. Accessed 12 January 2012.

Ols C., Victorsson J. \& Jonsell M. 2013: Saproxylic insect fauna in stumps on wet and dry soil: implications for stump harvest. - Forest Ecol. Manag. 290: 15-21.

RANIUS T. \& FAHRIG L. 2006: Targets for maintenance of dead wood for biodiversity conservation based on extinction thresholds. - Scand. J. Forest Res. 21: 201-208.

RANIUS T. \& JANSSON N. 2000: The influence of forest regrowth, original canopy cover and tree size on saproxylic beetles associated with old oaks. - Biol. Conserv. 95: 85-94.

SCHIEGG K. 2001: Saproxylic insect diversity of beech: limbs are richer than trunks. - Forest Ecol. Manag. 149: 295-304.

Similä M., Kouki J., Mönkkönen M., Sippola A.-L. \& Huhta E. 2006: Co-variation and indicators of species diversity: Can 
richness of forest-dwelling species be predicted in northern boreal forests? - Ecol. Indic. 6: 686-700.

Sobek S., Steffan-Dewenter I., Scherber C. \& Tscharntke T. 2009: Spatiotemporal changes of beetle communities across a tree diversity gradient. - Divers. Distrib. 15: 660-670.

Speight M.C.D. 1989: Saproxylic Invertebrates and their Conservation. Council of Europe, Strasbourg, $78 \mathrm{pp}$.

Stokland J.N. \& Sittonen J. 2012: Biodiversity in Dead Wood. Cambridge University Press, Cambridge, $524 \mathrm{pp}$.

Tropek R., Cerna I., Straka J., Cizek O. \& KonvičKa M. 2013: Is coal combustion the last chance for vanishing insects of inland drift sand dunes in Europe? - Biol. Conserv. 162: 60-64.
Ueda M. \& Shibata E. 2007: Host selection of small cedar longicorn beetle, Callidiellum rufipenne (Coleoptera: Cerambycidae), on Japanese cedar, Cryptomeria japonica, in terms of bark water content of host trees. - J. Forest Res. 12: 320-324.

UNI ISO 3130: 1985: Wood. Determination of Moisture Content for Physical and Mechanical Tests. http://www.iso.org/iso/ catalogue_detail.htm?csnumber $=8288$

Wikars L.O., Sahlin E. \& Ranius T. 2005: A comparison of three methods to estimate species richness of saproxylic beetles in logs and high stumps of Norway spruce. - Can. Entomol. 137: 304-324.

Received July 21, 2014; revised and accepted February 6, 2015 Prepublished online March 9, 2015 